\title{
Effects of brief and prolonged cold application on maximal isometric handgrip strength
}

\author{
DOI: https://doi.org/10.5114/pq.2021.105749
}

\author{
Hernán Andrés de la Barra ${ }^{1 \oplus}$, Jaime Opazo Cancino², Simón Tapia', Ignacio Pavez', Thiare Morales', \\ Mario Tapia ${ }^{1}$, Richard Liebano ${ }^{3 \oplus}$ \\ ${ }^{1}$ Universidad Andrés Bello, Santiago, Chile \\ 2 Universidad Diego Portales, Santiago, Chile \\ ${ }^{3}$ Universidade Federal de São Carlos, São Carlos, Brazil
}

\section{Abstract}

Introduction. Neuromuscular effects of cold highlight a decrease in nerve conduction velocity, which supports its analgesic impact, and muscle tone and strength reduction. However, it has been suggested that cold could increase strength with shorttime applications. The study aimed to compare the effects of brief and prolonged cold application on maximal isometric handgrip strength.

Methods. The controlled randomized clinical trial involved 112 volunteers (56 men and 56 women, mean age: $22 \pm 2.1$ years), randomly assigned to brief cooling group (BC, $n=36$ ), prolonged cooling group (PC, $n=40)$, and control group $(n=36)$. BC received quick icing in anterior forearm, while $\mathrm{PC}$ and control group received ice pack application and no treatment, respectively. Three sessions with 3-day intervals were performed. Handgrip strength was assessed with hand-held dynamometry before and after treatment. The main outcome was maximal isometric strength difference (MISdiff).

Results. There were statistically significant between-group differences in MISdiff in the 3 sessions (S1: $p=0.018 ; \mathrm{S} 2: p<0.001$; S3: $p<0.0001)$, showing a strength increase in $\mathrm{BC}(p<0.0001)$ and decrease in $\mathrm{PC}(p=0.025)$ at the end of the sessions. In addition, a post-intervention strength increase in BC was highlighted when analysing the sessions individually ( $\mathrm{S} 1: p=0.0003$; S2: $p=0.00147 ; \mathrm{S} 3: p=0.0001$ ).

Conclusions. Brief cold seems a good strategy to increase maximal isometric strength, although the underlying neurophysiological mechanisms must be further studied. Brief cooling could be considered as an ergogenic low-cost support when isometry training is required. In turn, a strength decrease after prolonged cooling was observed.

Key words: cryotherapy, ice, hand strength, isometric contraction, dynamometry

\section{Introduction}

Cryotherapy is a common intervention used in rehabilitation and other medicine areas, being a simple and low-cost therapy accepted as an effective non-pharmacological intervention for pain and inflammation [1]. Cold is usually applied for pain relief, oedema reduction, inflammatory process management, and spasticity decrease [2]. Most clinical studies support its analgesic and anti-inflammatory effects [2, 3], although there are different positions regarding cold application time [4-6]. Cryotherapy application can decrease deeper tissues temperature at the muscle and joint level, although this depends on the therapeutic modality used [2-4]. Cold is applied through different methods, such as ice cups, ice packs, cold baths, hydrocolloid packages (ice pads), cryopressure units, cold wet wraps, or refrigerant sprays [2]. The modalities differ in their specific heat capacity, cooling depth, and therapeutic effects duration, so the choice will depend on the therapeutic aim [2, 7-10].

Cold exerts its therapeutic effects by haemodynamic processes modulation, neuromuscular changes, and decreased metabolism [2]. These impacts depend on cold exposure time, skin and cold agent temperature difference, tissues thermal conductivity, adipose tissue thickness, and individual tolerance $[2,10,11]$. Haemodynamic effects are related to arteriolar vasoconstriction, while metabolic effects result from the slowing down of metabolic reactions [2]. In turn, neuro- muscular effects involve slower nerve conduction velocities (NCV) and an increase in nerve action potentials amplitudes. Decreased NCV would support the analgesic effect by slowing the conduction in free nerve endings [2, 12, 13]. In addition, muscle function has been shown to be sensitive to temperature variations, which indicates that its activation is modified not only by changes of neuromuscular spindles discharge or joint position, but also by lower skin receptors activation [2, 14]. Effects on sensory and motor nerve conduction have been compared for different cryotherapy modalities, showing that immersions in ice and water were most effective in decreasing muscle temperature and reducing strength [2, 13-16]. There is thus a direct relationship between NCV decrease and temperature, which is dependent on cold exposure [17]. NCV decrease resulting from superficial cold application is completely reversible at 15 minutes after the intervention, and the effect on muscle strength depends on the application time $[15,18,19]$. Ice applications lasting more than 30 minutes have shown a decrease in isometric muscle strength which recovers after 3 hours $[19,20]$. NCV diminution has supported cryotherapy as an intervention in motor disorders such as hypertonia and spasticity, with the aim of reducing muscle tone in order to facilitate movement and motor patterns in neurological conditions, achieved by affecting A-gamma motor neurons $(\mathrm{A} \gamma)$ conduction and neuromuscular spindles activity [20-24].

On the other hand, some research in healthy subjects and

Correspondence address: Hernán Andrés de la Barra Ortiz, Exercise and Rehabilitation Sciences Laboratory, School of Physical Therapy, Faculty of Rehabilitation Sciences, Universidad Andrés Bello, Santiago 7591538, Chile, e-mail: hdelabarra@unab.cland, handresdelabarra@yahoo.es, https://orcid.org/0000-0002-3927-1743 
hemiplegic patients have shown muscle activation after brief cold applications [2, 19]. Brief cooling is called a 'quick icing technique' (QI) and has been proposed to facilitate neuromuscular activity. This technique was first described by a physical therapist Margaret Rood, who used it as a treatment in patients with motor deficits generated by different neurological conditions [2, 9, 25]. QI consists of skin surface ice movement applications for times shorter than 5 minutes (usually 30-60 seconds); these are also referred to as cold shocks. QI basis is the facilitation of A-alpha motor neurons $(\mathrm{A} \alpha)$ mediated by the activation of cutaneous cold receptors, following the theory of the motor system's final pathway (MSFP), where A $\alpha$ motor neurons activation is influenced by both efferent and afferent stimuli [25-29]. That is how QI has been described as a strategy to facilitate muscle strength. This effect has been reported for isometric contraction in healthy subjects and to favour flaccid muscles contraction in patients with first motor neuron disorders [2, 19, 25-27]. These findings could support the QI technique where skin stimulation seems to be the key $[2,15,19,30]$. Unfortunately, evidence advocating the use of cold to increase neuromuscular activity and strength is scarce, and more research is necessary.

Thus, the purpose of this study was to compare the effectiveness of brief and prolonged cooling on maximal isometric handgrip strength, with the hypothesis that the QI technique would increase muscle strength, while prolonged cold application would reduce it.

\section{Subjects and methods}

\section{Participants}

Overall, 112 healthy volunteers ( 56 men and 56 women, mean age: $22 \pm 2.1$ years) were recruited. The participants were students of the School of Physical Therapy, Faculty of Rehabilitation Sciences, Universidad Andrés Bello. An invitation was provided to students through formal communication channels (mailing) and social networks, summoning 211 potential participants. The selection was based on a survey whose first part was structured in relation to the general demographic participant's data, including name, age, sex, body mass index (BMI), study year, and contact information (e-mail and telephone number). The second part of the survey consisted of closed questions involving the eligibility criteria. All subjects received verbal and written information about the study before giving their consent to participate.

\section{Selection criteria}

The inclusion criteria considered participants over 18 years of age without musculoskeletal conditions such as fractures, dislocations, sprains, or tears of the elbow, forearm, or hand of the dominant limb within the previous 6 months. Exclusion criteria involved the presence of pain or discomfort in handgrip, cold intolerance, pathologies such as cryoglobulinemia, Raynaud's disease or cold haemoglobinuria, rheumatoid diseases such as systemic lupus erythematosus or rheumatoid arthritis, and adverse reactions to ice cube test. The elimination criteria also comprised non-tolerance to cold intervention and non-completion of the evaluation protocol. A total of 114 participants were primarily selected, although 2 were eliminated when presenting a positive ice cube test result. Overall, 112 subjects were finally recruited and randomly assigned to 3 groups: brief cooling (BC, $n=36)$, prolonged cooling (PC, $n=40)$ and control $(n=36)$. The random-
Table 1. Characteristics of the study groups

\begin{tabular}{|c|c|c|c|c|}
\hline Variable & $\begin{array}{c}\mathrm{BC} \\
(n=36)\end{array}$ & $\begin{array}{c}\mathrm{PC} \\
(n=40)\end{array}$ & $\begin{array}{l}\text { Control } \\
(n=36)\end{array}$ & $p$ \\
\hline $\begin{array}{l}\operatorname{Sex}[n(\%)] \\
\text { men } \\
\text { women }\end{array}$ & $\begin{array}{l}18(32.1 \%) \\
18(32.1 \%)\end{array}$ & $\begin{array}{l}21(37.5 \%) \\
19(33.9 \%)\end{array}$ & $\begin{array}{l}17(30.4 \%) \\
19(33.9 \%)\end{array}$ & $0.9000^{+}$ \\
\hline $\begin{array}{l}\text { Age (years) } \\
(\text { mean } \pm S D)\end{array}$ & $22.3 \pm 2.4$ & $22.5 \pm 2.1$ & $22.0 \pm 4.1$ & $0.6101^{++}$ \\
\hline $\begin{array}{l}\mathrm{BMI}\left(\mathrm{kg} / \mathrm{m}^{2}\right) \\
(\text { mean } \pm S D)\end{array}$ & $24.5 \pm 5.0$ & $24.6 \pm 3.4$ & $24.3 \pm 4.1$ & $0.9471^{++}$ \\
\hline $\begin{array}{l}\operatorname{preMIS}_{\text {session1 }}(\mathrm{kg}) \\
(\text { mean } \pm S D)\end{array}$ & $34.8 \pm 11.1$ & $38.0 \pm 10.1$ & $36.6 \pm 14.2$ & $0.5221^{++}$ \\
\hline
\end{tabular}

$\mathrm{BC}$ - brief cooling, PC - prolonged cooling, BMI - body mass index, preMIS $_{\text {session } 1}$ - pre-intervention maximal isometric strength

Secondary variables were analysed for study groups to determine their homogeneity. The significance level was set at $p<0.05$.

+ The sex variable was analysed with a chi-squared test.

++ The variables of age, BMI, and preMIS ${ }_{\text {session } 1}$ were analysed with an ANOVA one-way parametric test.

ization was performed with opaque envelopes. The BC group was treated with QI in the anterior surface of the dominant forearm, while the PC group and control group received ice pack treatment and no intervention, respectively (Figure 1). The participants' demographic data were tabulated in Microsoft Excel ${ }^{\circledR} 2016$ (Table 1).

The secondary variable of sex was represented as frequency, while age and BMI were represented as averages with their respective standard deviations $(S D)$. The primary variable of pre-intervention maximal isometric strength (preMIS) was expressed as average with its $S D$. The homogeneity of the groups was analysed with the Stata v. 14 software.

\section{Procedures}

\section{Ice cube test}

This is a clinical test to determine cold sensitivity. The test consists in placing an ice cube on the forearm for 5 minutes, then removing it, and waiting for approximately 10 minutes for the recovery of normal skin temperature. The result is positive when pruritus or welts appear, indicating that there is sensitivity to cold. The test has a sensitivity of $83 \%$ and a specificity of $100 \%$ [31]. It was applied by a blinded physical therapist in an individual box. A total of 114 participants were evaluated before the randomization process, and 2 positive results were obtained.

\section{Dynamometry}

Hand-held dynamometry was chosen to measure isometric strength because it is a validated, reliable, and simple method [32-36]. The isometric strength was evaluated with the Jamar manual dynamometer manufactured by Lafayette Instrument Company, USA (model 63785). It provides a range of $0-90 \mathrm{~kg}(0-200 \mathrm{lb})$ of measurement [33, 34, 37]. The participants' maximal isometric strength difference (MISdiff) was obtained between pre- and post-treatment maximal isometric gripping strength (MIS) for each session. Grip strength evaluation involved 3 sessions with 3 -day intervals. The assessment was performed by a blinded physical therapist. The participant was sitting, with their shoulder adducted, elbow flexion of $90^{\circ}$, and forearm in neutral pronosupination. They were verbally instructed to make 3 grip attempts with their 


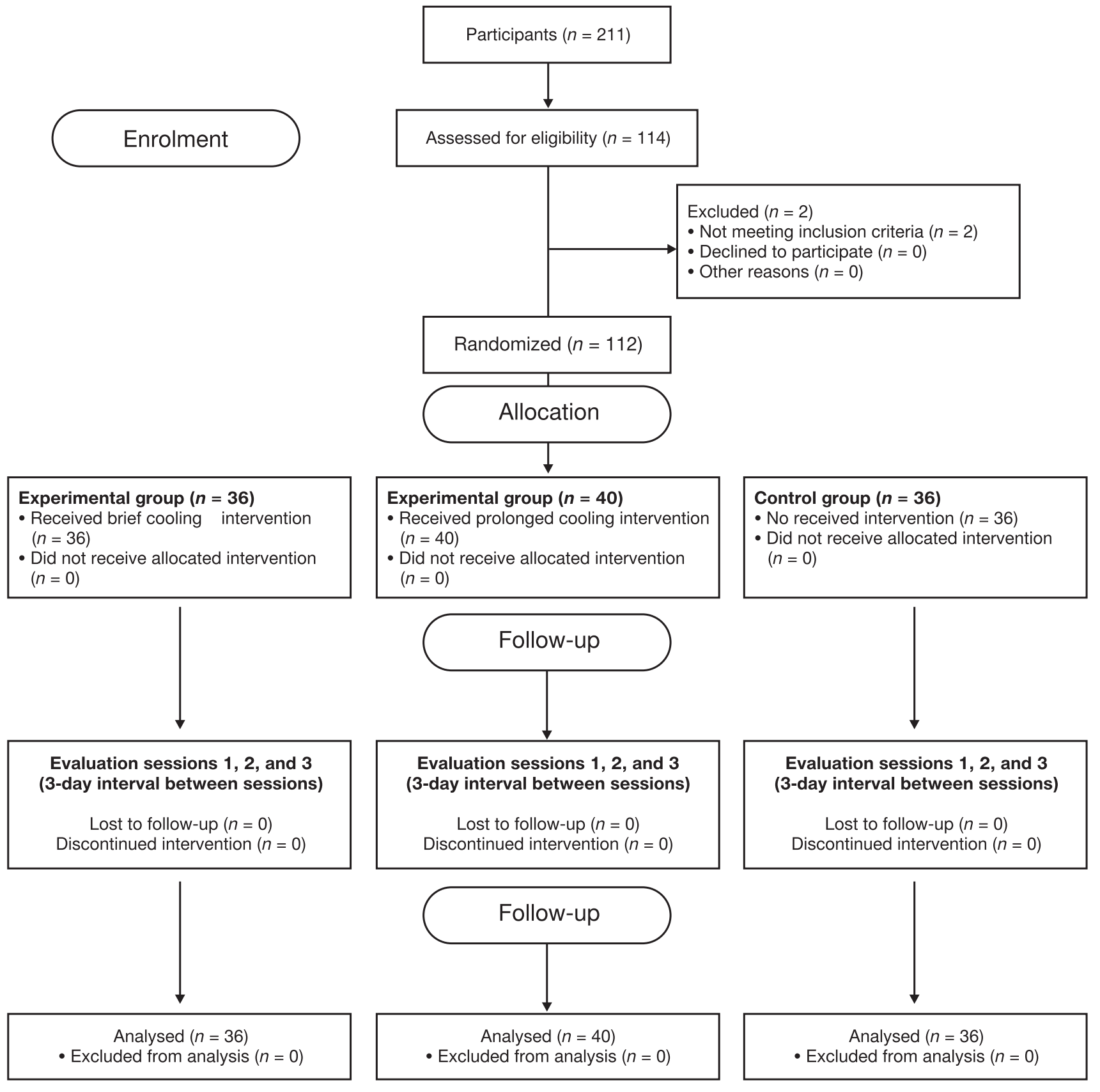

Figure 1. The study flowchart

dominant forearm, and the best MIS was registered in kilograms. The rest time between the attempts was 60 seconds to ensure muscle recovery $[31,36]$.

\section{Brief cooling (quick icing technique)}

The technique consisted in a direct application of ice cups brushes on the anterior dominant forearm surface for $60 \mathrm{sec}$ onds [2, 25, 26]. The test was performed by a blinded physical therapist in an individual box. The participant was sitting, with their shoulder adducted and forearm leaning on a table in supination. The subjects remained in the clinical box for 10 minutes, and the cold brushing was applied at minute 9 .

\section{Prolonged cooling}

The technique consisted in a direct application of an ice pack over the anterior region of the dominant forearm for 10 minutes. The intervention was performed by a blinded physical therapist in an individual box, with the participant in the same position as described for brief cooling.

\section{Statistical analysis}

Descriptive statistics including mean and $S D$ were provided for the variables of age, BMI, preMIS, postMIS, and MISdiff, while frequency (\%) was used for sex (Table 1). The Shapiro-Wilk test showed a normal distribution of the data so that an ANOVA one-way parametric test was applied to compare strength variables between the groups. After the analysis with ANOVA, the Bonferroni post-hoc test was conducted to compare the MISdiff between the groups and to determine statistically significant differences between them. Later, an analysis of intragroup MISdiff per session was performed by using the $t$-Student test. The significance level of 0.05 was considered for all statistical tests. The statistical analysis was performed with the Stata v. 13 software. 


\section{Ethical approval}

The research related to human use has complied with all the relevant national regulations and institutional policies, has followed the tenets of the Declaration of Helsinki, and has been approved by the Eastern Metropolitan Health Service Ethics Committee (reference number: 26082016). The study was registered at www.clinicaltrials.gov (identification number: NCT02884193).

\section{Informed consent}

Informed consent has been obtained from all individuals included in this study.

\section{Results}

Overall, 112 participants completed the study with no adverse effects. The sample was categorized in relation to sex, age, BMI, and preMIS (Table 1). Bartlett's test result for equal variances was not significant $(p>0.05)$ and the ANOVA test showed no differences for the variables, determining homogeneity of the groups.

\section{Intergroup maximal isometric strength difference}

MIS for each session was recorded before and after the intervention, providing pre- and post-treatment strength

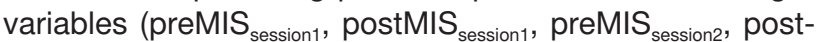
$\mathrm{MIS}_{\text {session2, }}$, preMIS $_{\text {session3 }}$, and postMIS session3 $)$. Strength changes between the sessions were assessed with the consideration of the baseline value defined as preMIS ${ }_{\text {session } 1}$. Strength differences between the sessions were determined from the difference between the post-treatment strength in each session (postMIS session1, postMIS $_{\text {session2, and postMIS }}$ session3 $_{\text {) }}$ and the baseline strength, with the resulting variables of MISdiff session1-1 $_{\text {, MISdiff }}$ session2-1 $_{\text {, and MISdiff }}$ session3-1 $($ Table 2).

Intergroup MISdiff between the sessions (Figure 2) showed statistically significant differences (MISdiff session1-1 $_{1}, p=0.0118$; $\mathrm{MISdiff}_{\text {session2-1 }}, p<0.0001$; MISdiff session3-1,$\left.p<0.0001\right)$. The $\mathrm{BC}$ group exhibited higher MISdiff compared with the other groups in the 3 sessions. For PC, negative strength values were shown for MISdiff when analysing the differences between sessions 2 and 3 in relation to baseline, which suggests a progressive decrease in strength.

Statistically significant differences were found by sex in the MISdiff between the 3 sessions for women (MISdiff ${ }_{\text {session 1-1, }}$, $p=0.0641 ;$ MISdiff $_{\text {session2-1 }}, p=0.0031 ;$ MISdiff $_{\text {session3-1 }}, p=$

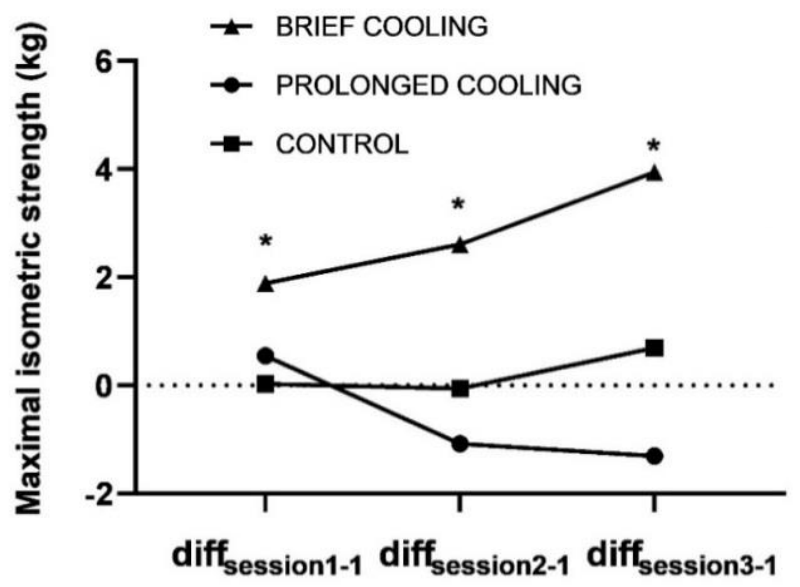

Evaluation sessions

\begin{tabular}{|c|c|c|c|c|c|}
\hline $\begin{array}{l}\delta \\
\infty\end{array}$ & $\begin{array}{l}0 \\
0 \\
0 \\
0\end{array}$ & 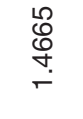 & 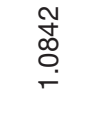 & $\begin{array}{l}\infty \\
\infty \\
\stackrel{\infty}{n} \\
\stackrel{+}{\leftarrow}\end{array}$ & \\
\hline $\begin{array}{l}\frac{0}{0} \\
\frac{0}{0} \\
\frac{0}{\omega} \\
\frac{N}{\omega}\end{array}$ & $\begin{array}{l}1 \\
0 \\
0 \\
0 \\
0 \\
0\end{array}$ & $\begin{array}{l}0 \\
\text { ల్ } \\
\text { N̦ } \\
0\end{array}$ & $\begin{array}{l}\infty \\
\stackrel{\infty}{\infty} \\
0 \\
i\end{array}$ & 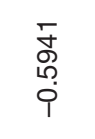 & 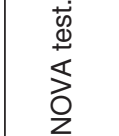 \\
\hline 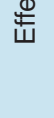 & 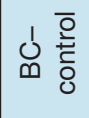 & $\begin{array}{l}\frac{0}{0} \\
\frac{0}{0} \\
0\end{array}$ & $\frac{\stackrel{9}{N}}{\frac{0}{+}}$ & $\frac{\stackrel{+}{+}}{\stackrel{+}{\leftarrow}}$ & $\begin{array}{l}\text { बे } \\
\sum_{1} \\
\stackrel{0}{0} \\
0\end{array}$ \\
\hline \multirow{3}{*}{$Q$} & 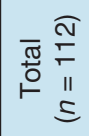 & $\begin{array}{l}\stackrel{*}{\infty} \\
\stackrel{0}{\sigma} \\
0 \\
0\end{array}$ & $\begin{array}{l}* \\
8 \\
8\end{array}$ & $\begin{array}{l}* \\
\stackrel{*}{0} \\
\stackrel{0}{0}\end{array}$ & $\begin{array}{l}\text { 秀 } \\
3 \\
\text { O } \\
\stackrel{\Phi}{5}\end{array}$ \\
\hline & 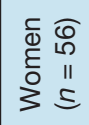 & \begin{tabular}{l}
$*$ \\
\multirow{0}{0}{} \\
0 \\
0
\end{tabular} & 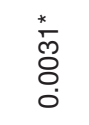 & $\begin{array}{l}\text { * } \\
\stackrel{0}{0} \\
0 \\
0\end{array}$ & $\begin{array}{l}\frac{T}{\Phi} \\
\frac{2}{0} \\
\frac{1}{0} \\
\underline{3}\end{array}$ \\
\hline & 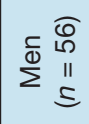 & $\frac{\varphi}{\frac{0}{\check{c}}}$ & $\begin{array}{l}\stackrel{*}{2} \\
\stackrel{0}{8} \\
0 \\
0\end{array}$ & 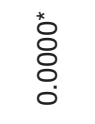 & 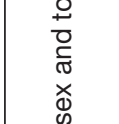 \\
\hline \multirow{3}{*}{$\begin{array}{l}\overline{0} \\
\text { 은 } \\
\text { O }\end{array}$} & 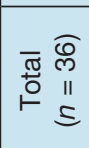 & $\begin{array}{l}N \\
i \\
+1 \\
0 \\
0\end{array}$ & $\begin{array}{l}\text { Na } \\
\text { ì } \\
+1 \\
\dot{\varphi}\end{array}$ & $\begin{array}{l}\hat{N} \\
+1 \\
+ \\
0\end{array}$ & $\begin{array}{l}\frac{7}{0} \\
0 \\
\frac{D}{0} \\
.0 \\
\frac{.0}{\pi} \\
0\end{array}$ \\
\hline & 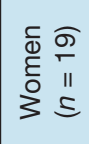 & $\begin{array}{l}\stackrel{0}{+} \\
+1 \\
+1 \\
\dot{1}\end{array}$ & $\begin{array}{l}\stackrel{0}{0} \\
+1 \\
+1 \\
\dot{\varphi}\end{array}$ & 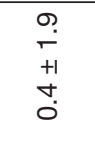 & $\begin{array}{l}\text { ह } \\
0 \\
0 \\
0 \\
0 \\
\text { 임 }\end{array}$ \\
\hline & $\underset{\frac{c}{0}}{\stackrel{N}{\Sigma}}$ & $\begin{array}{l}\text { O } \\
\stackrel{N}{ } \\
+1 \\
\sim \\
O\end{array}$ & $\begin{array}{l}\hat{N} \\
+1 \\
0 \\
0\end{array}$ & $\begin{array}{l}0 \\
\infty \\
+1 \\
+ \\
0 \\
+1\end{array}$ & 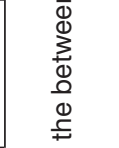 \\
\hline \multirow{3}{*}{ O } & 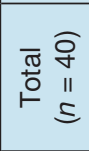 & $\begin{array}{l}\infty \\
i j \\
+1 \\
6 \\
0\end{array}$ & $\begin{array}{l}\hat{n} \\
+1 \\
+ \\
\bar{\varphi}\end{array}$ & $\begin{array}{l}\infty \\
\dot{m} \\
+1 \\
m \\
\stackrel{1}{1}\end{array}$ & 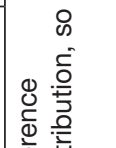 \\
\hline & 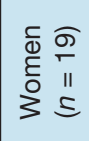 & $\begin{array}{l}\circ \\
i \\
+1 \\
\circ \\
0\end{array}$ & $\begin{array}{l}O \\
i \\
+1 \\
0 \\
O \\
i\end{array}$ & $\begin{array}{l}\stackrel{+}{u} \\
\stackrel{1}{+} \\
+1 \\
0 \\
i\end{array}$ & 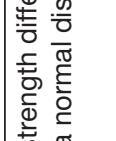 \\
\hline & 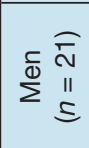 & $\begin{array}{l}\dot{+} \\
\stackrel{\infty}{ } \\
+1 \\
\stackrel{+}{+}\end{array}$ & $\begin{array}{l}\hat{+} \\
\dot{+} \\
+1 \\
\infty \\
\dot{T}\end{array}$ & $\begin{array}{l}\infty \\
\dot{+} \\
+1 \\
\circ \\
\stackrel{\gamma}{\gamma}\end{array}$ & 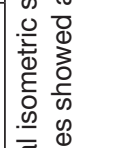 \\
\hline \multirow{3}{*}{ U్ల } & 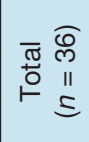 & 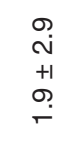 & $\begin{array}{l}\circ \\
\stackrel{\infty}{ } \\
+1 \\
0 \\
\stackrel{N}{N}\end{array}$ & $\begin{array}{l}\circ \\
\dot{m} \\
+1 \\
0 \\
\dot{m}\end{array}$ & 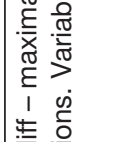 \\
\hline & 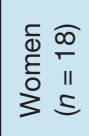 & $\begin{array}{l}\stackrel{+}{\sim} \\
\stackrel{+}{+} \\
\stackrel{\leftrightarrow}{r}\end{array}$ & $\begin{array}{l}\stackrel{0}{ } \\
\stackrel{+}{+1} \\
\stackrel{+}{+}\end{array}$ & $\begin{array}{l}\hat{m} \\
+1 \\
\stackrel{n}{m}\end{array}$ & 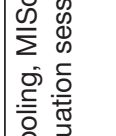 \\
\hline & $\stackrel{\frac{\infty}{\infty}}{\frac{\infty}{\|}}$ & $\begin{array}{l}m \\
\stackrel{m}{ } \\
+1 \\
+ \\
\dot{N}\end{array}$ & $\begin{array}{l}m \\
m \\
+1 \\
m \\
m\end{array}$ & $\begin{array}{l}\stackrel{9}{+} \\
\stackrel{+}{+} \\
\stackrel{+}{+}\end{array}$ & 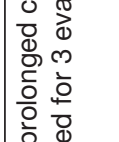 \\
\hline & $\frac{\frac{0}{0}}{\frac{\pi}{\frac{\pi}{2}}}$ & 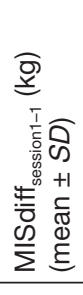 & 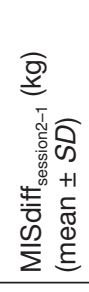 & 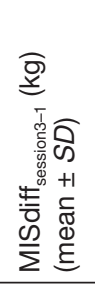 & 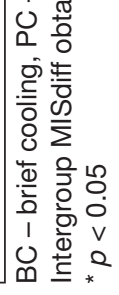 \\
\hline
\end{tabular}


Table 3. Intergroup comparison of maximal isometric strength difference between final evaluation and baseline by sex and total

\begin{tabular}{|c|c|c|c|c|c|c|c|}
\hline \multirow{2}{*}{\multicolumn{2}{|c|}{$\begin{array}{c}\text { Mean difference }(\mathrm{kg}) \\
p\end{array}$}} & \multicolumn{3}{|c|}{ PC } & \multicolumn{3}{|c|}{ Control } \\
\hline & & Men & Women & Total & Men & Women & Total \\
\hline \multirow{3}{*}{ Control } & Men & $\begin{array}{c}2.95 \\
0.049^{*}\end{array}$ & & & & & \\
\hline & Women & & $\begin{array}{c}1.00 \\
0.791\end{array}$ & & & & \\
\hline & Total & & & $\begin{array}{c}1.99 \\
0.025^{*}\end{array}$ & & & \\
\hline \multirow{3}{*}{$\mathrm{BC}$} & Men & $\begin{array}{c}6.62 \\
0.000^{*}\end{array}$ & & & $\begin{array}{c}3.67 \\
0.013^{*}\end{array}$ & & \\
\hline & Women & & $\begin{array}{c}3.80 \\
0.000^{*}\end{array}$ & & & $\begin{array}{c}2.80 \\
0.009^{\star}\end{array}$ & \\
\hline & Total & & & $\begin{array}{c}5.24 \\
0.0000^{*}\end{array}$ & & & $\begin{array}{c}3.25 \\
0.0000^{*}\end{array}$ \\
\hline
\end{tabular}

$\mathrm{PC}$ - prolonged cooling, BC - brief cooling

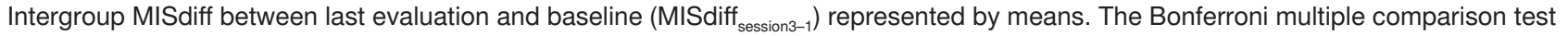
was used to analyse the difference of means between the groups.

${ }^{*} p<0.05$

Table 4. Intragroup maximal isometric strength differences

\begin{tabular}{|c|c|c|c|c|c|c|}
\hline Variable & $\begin{array}{c}\mathrm{BC} \\
(n=36)\end{array}$ & $p$ & $\begin{array}{c}\mathrm{PC} \\
(n=40)\end{array}$ & $p$ & $\begin{array}{l}\text { Control } \\
(n=36)\end{array}$ & $p$ \\
\hline $\begin{array}{l}\text { MISdiff }_{\text {session1-1 }}(\mathrm{kg}) \\
(\text { mean } \pm S D)\end{array}$ & $1.9 \pm 2.9$ & $0.0003^{*}$ & $0.6 \pm 2.8$ & 0.2612 & $0.0 \pm 2.2$ & 0.5000 \\
\hline $\begin{array}{l}\text { MISdiff }_{\text {session2-2 }}(\mathrm{kg}) \\
(\text { mean } \pm S D)\end{array}$ & $1.8 \pm 3.1$ & $0.0015^{\star}$ & $0.0 \pm 3.8$ & 0.7388 & $1.3 \pm 2.1$ & $0.0020^{*}$ \\
\hline $\begin{array}{l}\text { MISdiff }_{\text {session3-3 }}(\mathrm{kg}) \\
(\text { mean } \pm S D)\end{array}$ & $2.4 \pm 3.2$ & $0.0001^{*}$ & $0.1 \pm 4.3$ & 0.9061 & $0.3 \pm 2.7$ & 0.1885 \\
\hline
\end{tabular}

$\mathrm{BC}$ - brief cooling, PC - prolonged cooling, MISdiff - maximal isometric strength difference

Intragroup MISdiff per evaluation session. Comparison was performed with the $t$-Student test.

${ }^{*} p<0.05$

0.003 ) and in sessions 2 and 3 for men (MISdiff session2-1 $_{\text {, }}, p=$ 0.0005; MISdiff session3-1, $\left._{1}, p<0.0001\right)$. The results show an increase in strength for the BC group in MISdiff ${ }_{\text {session3-1, }}$, being greater in men than in women $(4.7 \pm 1.9 \mathrm{~kg}$ and $3.2 \pm 3.7 \mathrm{~kg}$, respectively). The PC group presented a decrease in strength

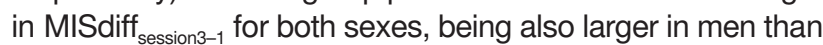
in women $(-1.8 \pm 4.7 \mathrm{~kg}$ and $-0.3 \pm 2.0 \mathrm{~kg}$, respectively).

\section{Intergroup maximal isometric strength difference} between final and baseline evaluation

The one-way ANOVA test showed statistically significant

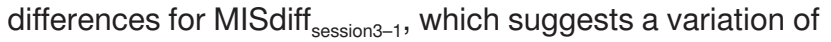
MIS between the groups considering the baseline strength $\left(\right.$ preMIS $\left._{\text {session1 }}\right)$. The Bonferroni multiple comparison test was used to analyse the differences of means between groups by sex and total (Table 3). It revealed statistically significant differences between all groups when comparing the means of MISdiff $_{\text {session3-1, }}$, although the greatest difference was found between the BC and PC groups (average strength difference: $5.24 \mathrm{~kg}, p<0.0001$ ), being statistically significant for both sexes, although greater for men than women (average strength difference: $6.62 \mathrm{~kg}$ and $3.80 \mathrm{~kg}$, respectively). The difference between means for MISdiff $_{\text {session3-1 }}$ also demonstrates statistically significant differences in favour of the $\mathrm{BC}$ group compared with the control group (average strength difference: $3.25 \mathrm{~kg}, p<0.0001$ ) and also when analysed by sex (average strength difference: $3.67 \mathrm{~kg}, p=0.0013$ for men; $2.80 \mathrm{~kg}, p=0.009$ for women).
Intragroup maximal isometric strength difference

Intragroup analysis of MISdiff for each evaluation day was performed with the $t$-Student test (MISdiff $_{\text {session1-1 }}$, MISdiff session2-2 $_{\text {, MISdiff }}$ session3-3) (Table 4). The results showed statistically significant changes in MISdiff for each evaluation session in the $\mathrm{BC}$ group, suggesting variations in strength between the pre- and post-intervention evaluation (MISdiff session1-1, $_{\text {, }}$, $p=0.0003$; MISdiff session2-2 $_{1}, p=0.0015 ;$ MISdiff $_{\text {session3-3 }}, p=$ $0.0001)$. The results obtained in the PC group for each session did not reveal statistically significant differences between pre- and post-intervention evaluations. The control group did not exhibit statistically significant differences for sessions 1 or 3 , but a significant change was observed for the second evaluation session $(p=0.0020)$.

\section{Discussion}

The decrease in NCV is one of the most studied neuromuscular effects of cryotherapy, being the basis of analgesic effects and decreased muscle tone described in physical therapy $[1-3,20,21,38,39]$. On the other hand, research on cold effect on muscle performance has demonstrated a decrease in strength, which would be sustained by decreased NCV, hypoperfusion, and cold ability to stiffen tissues by affecting their viscoelastic properties. Strength decrease is also dependent on the treatment time and the cryotherapy modality used [2, 4, 15, 38, 40]. Decreases in strength have been reported with cold applications longer than 5 minutes 
and preferably with cold-water immersion because it seems that they reach a greater depth to affect skeletal muscles $[2,4,10,13]$. Despite the above, some research has documented that isometric muscle strength increases with brief cold applications, which would be achieved by ice massage for less than 5 minutes [2, 19, 25, 26].

Therefore, the objective of this study was to investigate the effects of brief and prolonged cold on MIS in the context of the idea of cold application as a strength increase technique. The obtained results showed an increase in MISdiff for the hand-held dynamometer test in the BC group compared with the $\mathrm{PC}$ and control groups, demonstrating an effect size at the end of the 3 sessions of 1.1414 between the $B C$ and control groups, and 1.5188 between the $\mathrm{BC}$ and $\mathrm{PC}$ groups. It is interesting that these changes were appreciated in the first session and maintained and increased during the evaluation sessions, which would support the use of cold for intrasession and intersession strength increase. It should be noted that although there were increases in strength in both sexes in the BC group, these were greater among men, which reaffirms their better performance in hand dynamometry and faster neural adaptation mechanisms in strength gain [41-43]. That is how strength increases would support cold application to raise strength $[2,19,25,26]$. Unfortunately, the mechanisms proposed for these changes are not entirely clear, although a key would be the MSFP formed by all sensory afferences and convergent motor efferences in $A \alpha$ motor neurons. In this way, stimulation of cold receptors at the skin level would have positive feedback on A $\alpha$ motor neurons that control muscles underlying the skin, where the receptors are located. Stimulation of the sympathetic nervous system by the alert stimulus generated by cold has also been suggested. The sympathetic nervous system would not only be responsible for the cold-induced skin arteriolar vasoconstriction effect but would also facilitate vasodilation at the muscular level and the discharge of Ay motor neurons with a subsequent activation of MSFP [2, 19, 25, 26, 38, 40]. Furthermore, the decrease in strength obtained in the PC group after the 3 sessions reaffirms the effect of NCV reduction associated with cold. Although strength decrease did not show intrasession changes, there was a decrease when comparing baseline values with those achieved in the third evaluation $[2,3,5,15,18,23,40]$.

With the results and differences in MISdiff between the groups, it is ruled out that these increases in strength were due to the repetition of the test (training), since all participants performed the same number of attempts and sessions, with the same intrasession and intersession muscle recovery. It is also ruled out that the decrease in muscle performance in the PC group was due to fatigue, as the recommendations of time intervals between the dynamometry attempts were followed to ensure muscle recovery [37].

The obtained results are interesting; they expand the possibilities of intervention with cryotherapy and support cold application as a low-cost and highly available ergogenic alternative to recover isometric strength. Undoubtedly, isometry is an important component of muscle training, but it would be noteworthy to carry out new protocols that evaluate other phases of muscle contraction (concentric or eccentric). The new protocols could include different cold application times to establish a cut-off point when the cold facilitates or affects the strength, as well as its minimum dose. It would also be interesting to compare brief cooling with other strength promotion strategies, such as electrotherapy.

\section{Limitations}

Sample size calculation was not possible because the few studies of brief cooling did not report enough information to determine their effect size. This information is necessary to calculate the number participants required $(1-\beta)$. With this consideration, post-hoc statistical power of the 2 interventions was estimated in relation to the observed change differences taking the control group as reference. For this analysis, MISdiff session3-1 $_{1}$ was assumed as the final change variable after the 3 sessions. A statistical power of 0.7437 was obtained for PC and 0.9987 for BC $(\alpha=0.05)$. This information will allow estimating sample sizes for new protocols. Another limitation was the number of treatment sessions performed; perhaps a greater number of sessions could generate potentiation of prolonged and brief cold effects on strength. The study sought to evaluate short-term effects of cold, for which 3 sessions were enough.

\section{Conclusions}

This study shows that brief cooling increased maximal isometric strength as evaluated in the manual dynamometric test. Therefore, cold could become a low-cost alternative for physical therapists when they want to work on muscle strength. Although the neurophysiological mechanisms are not entirely clear, the results reaffirm what several studies initiated long time ago. It is proposed to carry out new protocols, assessing other phases of muscle contraction, and perform comparisons with other strength-increase strategies used in physical therapy, revealing cryotherapy effects to improve muscle performance as a natural and non-invasive ergogenic alternative. In addition, the effects of prolonged cold consisted in reducing the isometric strength of grip.

\section{Disclosure statement}

No author has any financial interest or received any financial benefit from this research.

\section{Conflict of interest}

The authors state no conflict of interest.

\section{References}

1. Aciksoz S, Akyuz A, Tunay S. The effect of self-administered superficial local hot and cold application methods on pain, functional status and quality of life in primary knee osteoarthritis patients. J Clin Nurs. 2017; 26(23-24):5179-5190; doi: 10.1111/jocn.14070.

2. Cameron MH. Superficial cold and heat. In: Cameron MH, Physical agents in rehabilitation. From research to practice, $4^{\text {th }}$ ed. St. Louis: Saunders; 2012; 129-172.

3. Swenson C, Swärd L, Karlsson J. Cryotherapy in sports medicine. Scand J Med Sci Sports. 1996;6(4):193-200; doi: 10.1111/j.1600-0838.1996.tb00090.x.

4. Herrera E, Sandoval MC, Camargo DM, Salvini TF. Effect of walking and resting after three cryotherapy modalities on the recovery of sensory and motor nerve conduction velocity in healthy subjects. Rev Bras Fisioter. 2011; 15(3):233-240; doi: 10.1590/s1413-35552011000300010.

5. Mac Auley DC. Ice therapy: how good is the evidence? Int J Sports Med. 2001;22(5):379-384; doi: 10.1055/s2001-15656.

6. Leite M, Ribeiro F. Liquid Ice fails to cool the skin surface as effectively as crushed ice in a wet towel. Physiother Theory Pract. 2010;26(6):393-398; doi: 10.3109/09593 980903229240. 
7. Ostrowski J, Purchio A, Beck M, Leisinger J. Effectiveness of salted ice bag versus cryocompression on decreasing intramuscular and skin temperature. J Sport Rehabil. 2019;28(2):120-125; doi: 10.1123/jsr.2017-0173.

8. Tomchuk D, Rubley MD, Holcomb WR, Guadagnoli M, Tarno JM. The magnitude of tissue cooling during cryotherapy with varied types of compression. J Athl Train. 2010;45(3):230-237; doi: 10.4085/1062-6050-45.3.230.

9. Love HN, Pritchard KA, Hart JM, Saliba SA. Cryotherapy effects, part 1: Comparison of skin temperatures and patient-reported sensations for different modes of administration. Int J Athl Ther Train. 2013;18(5):22-30; doi: 10.1123/ijatt.18.5.22.

10. Cataldi JK, Pritchard KA, Hart JM, Saliba SA. Cryotherapy effects, part 2: Time to numbness onset and numbness duration. Int J Athl Ther Train. 2013;18(5):26-28; doi: 10.1123/ijatt.18.5.26.

11. Otte JW, Merrick MA, Ingersoll CD, Cordova ML. Subcutaneous adipose tissue thickness alters cooling time during cryotherapy. Arch Phys Med Rehabil. 2002;83(11): 1501-1505; doi: 10.1053/apmr.2002.34833.

12. Dhavalikar M, Narkeesh A, Gupta N. Effect of skin temperature on nerve conduction velocity and reliability of temperature correction formula in Indian females. J Exerc Sci Physiother. 2009;5(1):24-29.

13. McMeeken J, Lewis MM, Cocks S. Effects of cooling with simulated ice on skin temperature and nerve conduction velocity. Aust J Physiother. 1984;30(4):111-114; doi: 10.1016/S0004-9514(14)60682-6.

14. Lowdon BJ, Moore RJ. Temperature changes in muscle during cold therapy and following a sustained contraction. Aust J Sports Med. 1977;2:9-12.

15. Herrera E, Sandoval MC, Camargo DM, Salvini TF. Motor and sensory nerve conduction are affected differently by ice pack, ice massage, and cold water immersion. Phys Ther. 2010;90(4):581-591; doi: 10.2522/ptj.20090131.

16. Clarke RS, Hellon RF, Lind AR. The duration of sustained contractions of the human forearm at different muscle temperatures. J Physiol. 1958;143(3):454-473; doi: 10.1113/jphysiol.1958.sp006071.

17. Zhang Z, Lyon TD, Kadow BT, Shen B, Wang J, Lee A, et al. Conduction block of mammalian myelinated nerve by local cooling to $15-30^{\circ} \mathrm{C}$ after a brief heating. J Neurophysiol. 2016;115(3):1436-1445; doi: 10.1152/jn.00954. 2015.

18. Lee JM, Warren MP, Mason SM. Effects of ice on nerve conduction velocity. Physiotherapy. 1978;64(1):2-6.

19. McGown HL. Effects of cold application on maximal isometric contraction. Phys Ther. 1967;47(3):185-192; doi: 10.1093/ptj/47.3.185.

20. Knuttsson E. Topical cryotherapy in spasticity. Scand J Rehab Med. 1970;2(4):159-163; doi: 10.2340/1650197 7197024159163.

21. Carmona Alcantara C, Blanco J, De Oliveira LM, Sávio Ribeiro PF, Herrera E, Nakagawa TH, et al. Cryotherapy reduces muscle hypertonia, but does not affect lower limb strength or gait kinematics post-stroke: a randomized controlled crossover study. Top Stroke Rehabil. 2019; 26(4):267-280; doi: 10.1080/10749357.2019.1593613.

22. Cavalcanti Garcia L, Carmona Alcântara C, Lopes Santos G, Almeida Monção JV, Russo TL. Cryotherapy reduces muscle spasticity but does not affect proprioception in ischemic stroke: a randomized sham-controlled crossover study. Am J Phys Med Rehabil. 2019;98(1): 51-57; doi: 10.1097/PHM.0000000000001024.

23. Santos MTBT, Oliveira LM. Use of cryotherapy to enhance mouth opening in patients with cerebral palsy. Spec Care Dentist. 2004;24(4):232-234; doi: 10.1111/j.1754-4505. 2004.tb01698.x.

24. Germano AMC, Schlee G, Milani TL. Effect of cooling foot sole skin receptors on Achilles tendon reflex. Muscle Nerve. 2016;53(6):965-971; doi: 10.1002/mus.24994.

25. Goff B. The application of recent advances in neurophysiology to Miss M. Rood's concept of neuromuscular facilitation. Physiotherapy. 1972;58(12):409-415.

26. Surburg PR, Schrader JW. Proprioceptive neuromuscular facilitation techniques in sports medicine: a reassessment. J Athl Train. 1997;32(1):34-39.

27. Hrbek J. Proprioceptive-motor circuits governing striated muscles. Structure, function and disorders. Praha: SPN; 1981.

28. Manuel M, Zytnicki D. Alpha, beta and gamma motoneurons: functional diversity in the motor system's final pathway. J Integr Neurosci. 2011;10(3):243-276; doi: 10.1142/S0219635211002786.

29. Hounsgaard J. Motor neurons. Compr Physiol. 2017;7(2): 463-484; doi: 10.1002/cphy.c160025.

30. Vieira A, Oliveira AB, Costa JR, Herrera E, Salvini TF. Cold modalities with different thermodynamic properties have similar effects on muscular performance and activation. Int J Sports Med. 2013;34(10):873-880; doi: 10.1055/s-0032-1333283.

31. De la Barra Ortiz HA, Opazo Cancino J, Minzer Goluboff N, Andrade Obando G, Herrera Jara M, González Vera $M$. Effects of ascending and descending direct current on grip strength assessed through dynamometry and myofeedback: a randomized controlled trial. Physiother Quart. 2020;28(2):1-8; doi: 10.5114/pq.2020.92471.

32. Bohannon RW. Dynamometer measurements of handgrip strength predict multiple outcomes. Percept Mot Skills. 2001;93(2):323-328; doi: 10.2466/pms.2001.93. 2.323.

33. Chopp-Hurley JN, Wiebenga EG, Gatti AA, Maly MR. Investigating the test-retest reliability and validity of handheld dynamometry for measuring knee strength in older women with knee osteoarthritis. Physiother Can. 2019; 71(3):231-238; doi: 10.3138/ptc-2018-0051.

34. Bellace JV, Healy D, Besser MP, Byron T, Hohman L. Validity of the Dexter Evaluation System's Jamar dynamometer attachment for assessment of hand grip strength in normal population. J Hand Ther. 2000;13(1):46-51; doi: 10.1016/S0894-1130(00)80052-6.

35. Roberts HC, Denison HJ, Martin HJ, Patel HP, Syddall H, Cooper $\mathrm{C}$, et al. A review of the measurement of grip strength in clinical and epidemiological studies: towards a standardised approach. Age Aging. 2011;40(4):423429; doi: 10.1093/ageing/afr051.

36. Schrama PPM, Stenneberg MS, Lucas C, van Trijffel E. Intraexaminer reliability of hand-held dynamometry in the upper extremity: a systematic review. Arch Phys Med Rehabil. 2014;95(12):2444-2469; doi: 10.1016/j. apmr.2014.05.019.

37. Watanabe T, Owashi K, Kanauchi Y, Mura N, Takahara M, Ogino T. The short-term reliability of grip strength measurement and the effects of posture and grip span. $J$ Hand Surg Am. 2005;30(3):603-609; doi: 10.1016/j. jhsa.2004.12.007.

38. Hawkins SW, Hawkins JR. Clinical applications of cryotherapy among sports physical therapists. Int J Sports Phys Ther. 2016;11(1):141-148.

39. Nadler SF, Weingand K, Kruse RJ. The physiologic basis and clinical applications of cryotherapy and thermother- 
apy for the pain practitioner. Pain Physician. 2004;7(3): 395-399; doi: 10.36076/ppj.2004/7/395.

40. Mallette MM, Green LA, Gabriel DA, Cheung SS. The effects of local forearm muscle cooling on motor unit properties. Eur J Appl Physiol. 2018;118(2):401-410; doi: 10.1007/s00421-017-3782-y.

41. Yu R, Ong S, Cheung O, Leung J, Woo J. Reference values of grip strength, prevalence of low grip strength, and factors affecting grip strength values in Chinese adults. J Am Med Dir Assoc. 2017;18(6):551.e9-551.e16; doi: 10.1016/j.jamda.2017.03.006.

42. Wang Y-C, Bohannon RW, Li X, Sindhu B, Kapellusch $J$. Hand-grip strength: normative reference values and equations for individuals 18 to 85 years of age residing in the United States. J Orthop Sports Phys Ther. 2018; 48(9):685-693; doi: 10.2519/jospt.2018.7851.

43. Kamen G. Neural issues in the control of muscular strength. Res Q Exerc Sport. 2004;75(1):3-8; doi: 10.1080/ 02701367.2004.10609127. 